\title{
Hydrogen Evolution Reaction on the Oxidized Surfaces of the Fe-Based Amorphous Alloys
}

\author{
M.-O.M. DANYLiAK ${ }^{a}$, L.M. BOICHYShYN ${ }^{a, *}$ AND N.L. PANDiAK ${ }^{b}$ \\ ${ }^{a}$ Faculty of Chemistry, Ivan Franko National University of Lviv, Lviv, 79005, Ukraine \\ ${ }^{b}$ The National Forestry and Wood-Technology University of Ukraine, Lviv, 79057, Ukraine
}

\begin{abstract}
Electrochemical hydrogen evolution on oxidized electrodes of the amorphous metallic alloys $\mathrm{Fe}_{82} \mathrm{Nb}_{2} \mathrm{~B}_{14} \mathrm{RE}_{2}$ $(\mathrm{RE}=\mathrm{Tb}, \mathrm{Dy})$ in $5.0 \mathrm{M} \mathrm{KOH}$ aqueous solution in the temperature range $298-313 \pm 0.5 \mathrm{~K}$ has been investigated. A sample $\mathrm{Fe}_{84} \mathrm{Nb}_{2} \mathrm{~B}_{14}$ was used as reference alloy. The highest corrosion resistance during multiple scanning of the potential exhibited the alloys doped by terbium and dysprosium. High values of the exchange currents, characterizing catalytic ability and corrosion resistance characterize $\mathrm{Fe}_{82} \mathrm{Nb}_{2} \mathrm{~B}_{14} \mathrm{RE}_{2}$ amorphous alloys as promising electrode materials for hydrogen evolution reaction.
\end{abstract}

DOI: 10.12693/APhysPolA.133.1103

PACS/topics: amorphous alloys, oxidized surfaces, rare-earth metals, hydrogen evolution reaction, electrocatalysis

\section{Introduction}

The hydrogen evolution reaction (HER) on different metals and alloys in alkaline aqueous solutions has been attracting much attention for years because of its importance for fundamental research and technological application. Development of ecological energy technologies (fuel elements, metal hydrides accumulating systems, etc.) confirms the advantages of the use of hydrogen as an energy source. Taking into account that hydrogen deposits in organic compounds, in water and its derivatives are, practically, inexhaustible, a problem of effective and ecological conduction of HER is actual. The electrocatalytic HER on various electrode materials including different amorphous metallic alloys (AMA) has been intensively studied [1].

Among the other Fe-based amorphous alloys with small additions (1-3 at.\%) of $\mathrm{Nb}, \mathrm{V}, \mathrm{Mo}, \mathrm{W}$ and other transition elements, and of some $p$-elements B, Si exhibited peculiar high corrosive durability in alkaline solutions $[2,3]$. This shows them to be perspective materials for practical application. Amorphous alloys which contain plenty of such elements undergo autopassivation in aggressive solutions [4]. The experimental data indicate also that alloying Fe-based amorphous alloys with rare earth metals (1-5 at.\%) increases electrocatalytic activity of alloys in HER in alkaline aqueous solutions $[5,6]$. One of the important points when considering the enhancement of oxidation resistance in metallic glass is the formation of the oxide layer with an amorphous structure at the early stage of the oxidation process [2]. Since the atoms are more densely packed in the amorphous structure than in the counterpart crystalline structure, the transport of oxygen ion in the amorphous oxide layer is more difficult than in the counterpart crystalline oxide

*corresponding author; e-mail: Iboichyshyn@yahoo.com layer. Therefore, the thermal stability of the amorphous oxide has a crucial effect on the oxidation resistance of metallic glass at high temperature. Recently, it has been reported that $100 \mathrm{~nm}$ thick amorphous oxide layer forms during annealing $\mathrm{Al}_{87} \mathrm{Ni}_{3} \mathrm{Y}_{10}$ metallic glass at $873 \mathrm{~K}$ for $15 \mathrm{~h}$ [6]. The presence of a small amount of yttrium in the amorphous oxide layer indicates that the diffusivity of oxygen ion is greatly suppressed by minor alloying effect. Therefore, minor alloying in the oxide layer can significantly affect the thermal stability of the amorphous oxide layer [7].

Different amorphous and nanocrystalline metallic alloys have been studied as electrocatalysts for HER in alkaline water solutions. The highly defective microstructure of the nanocrystalline materials and the coordinatively unsaturated surface atoms in the AMA are prerequisites for attractive catalytic properties [8, 9]. Characteristics of amorphous and nanocrystalline metallic electrodes can be modified by changing an element composition and geometric surface area [10-14].

The aim of this study was to investigate the influence of the oxide-hydroxide layers formed by different conditions on the electrocatalytic activity of the $\mathrm{Fe}_{82} \mathrm{Nb}_{2} \mathrm{~B}_{14} \mathrm{RE}_{2}$ $(\mathrm{RE}=\mathrm{Tb}, \mathrm{Dy}) \mathrm{AMA}$-electrodes for HER.

\section{Experimental details}

The ribbons of three AMA were prepared by melt spinning technique. A basic ternary sample $\mathrm{Fe}_{84} \mathrm{Nb}_{2} \mathrm{~B}_{14}$ was alloyed with 2 at. $\%$ of $\mathrm{RE}=\mathrm{Tb}$ or $\mathrm{Dy}: \mathrm{Fe}_{82} \mathrm{Nb}_{2} \mathrm{~B}_{14} \mathrm{~Tb}_{2}$, $\mathrm{Fe}_{82} \mathrm{Nb}_{2} \mathrm{~B}_{14} \mathrm{Dy}_{2}$. Melted alloys under argon and surplus pressure were spun on the external surface of massive disk-cooler. The temperature of melting and overheat of alloys was controlled by immersion thermocouple BP5/20 with millivoltmeter registration. The initial elements of high purity, not less than 99.9 mass\%, were used. The ribbons received were $0.2 \div 1 \mathrm{~cm}$ wide and $35 \mu \mathrm{m}$ thick.

Change of corrosive stability of AMA in an aggressive environment at different temperatures was investigated by voltammetry in the potentiodynamic mode with 
automatic involution in time of setted potential of surface of alloy using Potentiostat EP 20A. A conventional, three-electrode cell was used in electrochemical investigations [13]. A large area platinum foil with area of $2.0 \mathrm{~cm}^{2}$ served as counter electrode and a saturated calomel electrode (SCE) was used as reference electrode. The geometrical area of all tested AMA electrodes was $0.40 \mathrm{~cm}^{2}$. Polarization curves of solubility of AMA were recorded in $5 \mathrm{M} \mathrm{KOH}$ aqueous solutions at the scan rate of $50 \mathrm{mV} / \mathrm{s}$. Electrochemical parameters of corrosion of amorphous alloys were calculated using a Tafel equation $\eta=a+b \log i$, where $\eta$ is overpotential [V], $a$ and $b$ are constants [V], $i$ is current density $\left[\mathrm{A} \mathrm{cm}^{-2}\right]$.

Catalytic activity of the alloys in the process of hydrogen evolution was estimated after the identified peaks on cyclic voltammetry curves (the chart of galvanic element is the same). Optimization of speed of polarization of electrodes from 20 to $100 \mathrm{mV} / \mathrm{s}$ was conducted with the purpose of choice of reproducibility of voltammetry curves. All the experiments were carried out in the temperature range from 298 to $313 \pm 0.5 \mathrm{~K}$.

Surface scanning of the initial samples and the samples after electrocatalytic reaction was performed using electronic microscope-microanalyzer REMMA-102-02 with electrons beam energy $0.2-40 \mathrm{kV}$, magnification 6000 , the resolution was about $5.0 \mathrm{~nm}$.

\section{Results and discussion}

Voltammograms of oxide-reduction processes of AMAelectrodes in $5.0 \mathrm{M} \mathrm{KOH}$ aqueous solution at different sweep speed of the potential were carried out to determine the number of stages of electrochemical processes. Cyclic voltammograms of $\mathrm{Fe}_{84} \mathrm{Nb}_{2} \mathrm{~B}_{14}$ amorphous alloy at 20,50 , and $100 \mathrm{mV} / \mathrm{s}$ scanned speed of outer potential in the range from -1.0 to +0.4 are presented in Fig. 1 . The potentials and the current densities of all maxima on voltammograms were identified and the dependences $E=f\left(V_{\text {scan }}\right)$ and $i=f\left(V_{\text {scan }}\right)$ were recorded. These data are presented in Table I. In order to select the optimal scanning speed of the external potential for further research of the AMA electrodes in the HER, the staging of electrochemical transformations was analyzed. As can
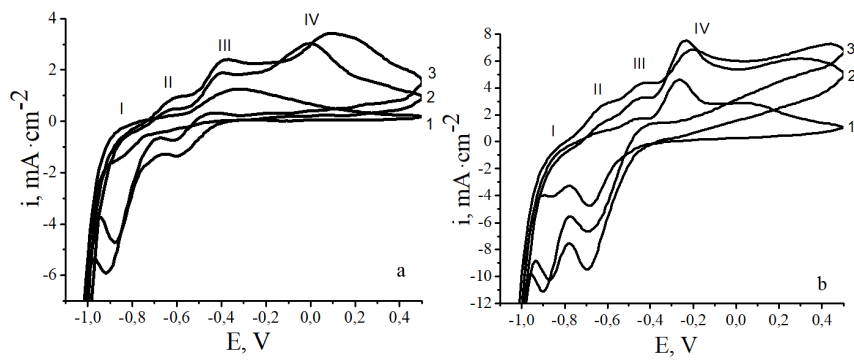

Fig. 1. Cyclic voltammograms of $\mathrm{Fe}_{84} \mathrm{Nb}_{2} \mathrm{~B}_{14}$ amorphous alloy (first (a) and fifth (b) cycle) registered at different scanned speed $(\mathrm{mV} / \mathrm{s})$ of outer potential: 1 $20,2-50,3-100$ in $5.0 \mathrm{M} \mathrm{KOH}$ aqueous solution. IIV - stages of electrochemical process. $T=293 \pm 0.5 \mathrm{~K}$.
TABLE I

Dependence of the electrochemical potential $(E, \mathrm{mV})$ and current density $\left(i, \mathrm{~mA} / \mathrm{cm}^{-2}\right)$ of the electrochemical reaction on the $\mathrm{Fe}_{84} \mathrm{Nb}_{2} \mathrm{~B}_{14}$ electrode in $5.0 \mathrm{M} \mathrm{KOH}$ aqueous solution at different scanning speed $(\mathrm{mV} / \mathrm{s})$ of the external potential in the range from -1.0 to $+0.4 \mathrm{~V}$, $T=293 \pm 0.5 \mathrm{~K}$.

\begin{tabular}{c|c|c|c|c|c}
\hline \hline \multirow{2}{*}{ Scanning speed } & \multirow{2}{*}{ Stage } & \multicolumn{2}{|c|}{ Cycle 1 } & \multicolumn{2}{c}{ Cycle 5 } \\
\cline { 3 - 6 } & & $E$ & $i$ & $E$ & $i$ \\
\hline \multirow{5}{*}{20} & I & -850 & 0.32 & - & - \\
& II & - & - & - & - \\
& III & -344 & 1.27 & -455 & 1.70 \\
& IV & - & - & -268 & 4.55 \\
\hline \multirow{5}{*}{50} & I & -830 & 0.65 & -801 & 0.94 \\
& II & -635 & 0.45 & -630 & 1.31 \\
& III & -397 & 1.88 & -446 & 3.22 \\
& IV & -7 & 3.04 & -234 & 7.47 \\
\hline \multirow{5}{*}{100} & I & -845 & 0.62 & -827 & 0.35 \\
& II & -612 & 0.88 & -632 & 2.58 \\
& III & -390 & 2.40 & -443 & 4.29 \\
& IV & 110 & 3.44 & -202 & 6.84
\end{tabular}

be seen from Fig. 1, the potential sweep speed of $20 \mathrm{mV} / \mathrm{s}$ does not allow to capture all the stages (I-IV) of electrochemical oxidation and reduction of the surface of AMA electrodes.

At a speed of $100 \mathrm{mV} / \mathrm{s}$ oxidation peaks corresponding to the detected stages are less clear, which reduces the reliability of determining their electrochemical parameters. The staging of electrochemical transformations can be resolved optimally at a scanning speed of an external potential of $50 \mathrm{mV} / \mathrm{s}$.

Oxide-reduction processes on AMA in 5.0 M KOH solution were identified from the potentials of the experimental $\left(E_{\text {exp }}, \mathrm{mV}\right)$ and theoretical $\left(E_{\text {theor }}, \mathrm{mV}\right)$ peaks on the Pourbaix diagrams [15]. Electrochemical oxidation characteristics of AMA electrodes are given in Table II. From the results shown in Table II, it can be seen that on the surface of AMA in a solution of $\mathrm{pH}=13.7$ oxides and hydro-oxide of $\mathrm{Fe}$ and $\mathrm{Nb}$ are formed. Therefore, the following investigation of the reaction of hydrogen evolution carried out initially and independently after immersing of the samples for $24 \mathrm{~h}$ in $5.0 \mathrm{M} \mathrm{KOH}$ solution.

In diluted alkaline solutions, active processes of formating the developed surface layers on the alloys take place. In 5.0 M KOH solution the initial surface of AMA does not change in time (see Table III). Alloying AMA by rare earth elements promotes preservation and conservation of the electrode surface. From the results, it is visible on the values of the density of exchange current specified in 5.0 M KOH solution for AMA-electrodes alloyed with $\mathrm{Tb}$ and Dy.

After synthesis by the melt spinning method, the initial surface of AMA oxidizes as a result with contact with air. As a result, for all initial alloys it is covered with thin homogeneous layers (Fig. 2a). The testing of electrocatalytic ability of all AMA-electrodes was carried out 
Electrochemical oxidation characteristics of AMA electrodes, $T=293 \pm 0.5 \mathrm{~K}$ [15].

TABLE II

\begin{tabular}{c|l|l|c|c}
\hline \hline Element & \multicolumn{1}{|c|}{ Reaction } & \multicolumn{1}{|c}{ Equation for $E_{0}$} & $E_{\text {theor }}$ & $E_{\text {exp }}$ \\
\hline & $2 \mathrm{Fe}+3 \mathrm{H}_{2} \mathrm{O}=\mathrm{Fe}_{2} \mathrm{O}_{3}+6 \mathrm{H}^{+}+6 \mathrm{e}^{-}$ & $E_{0}=-0.051-0.0591 \mathrm{pH}$ & -840 & -860 \\
& $2 \mathrm{FeO}+\mathrm{H}_{2} \mathrm{O}=\mathrm{Fe}_{2} \mathrm{O}_{3}+2 \mathrm{H}^{+}+2 \mathrm{e}^{-}$ & $E_{0}=-0.057-0.0591 \mathrm{pH}$ & -840 & -860 \\
$\mathrm{Fe}$ & $\mathrm{Fe}+\mathrm{H}_{2} \mathrm{O}=\mathrm{FeO}+2 \mathrm{H}^{+}+2 \mathrm{e}^{-}$ & $E_{0}=--0.017-0.0591 \mathrm{pH}$ & -800 & -830 \\
& $\mathrm{Fe}^{3+} / \mathrm{FeO}_{4}^{2-}$ & $E_{0}=1.7-0.158 \mathrm{pH}$ & -400 & -440 \\
& $\mathrm{Fe}^{2+} / \mathrm{Fe}(\mathrm{OH})_{2}^{+}$ & $E_{0}=1.191-0.1182 \mathrm{pH}$ & -380 & -360 \\
\hline $\mathrm{Nb}$ & $2 \mathrm{NbO}_{2}+\mathrm{H}_{2} \mathrm{O}=\mathrm{Nb}_{2} \mathrm{O}_{5}+2 \mathrm{H}^{+}+2 \mathrm{e}^{-}$ & $E_{0}=0.289-0.0591 \mathrm{pH}$ & -497 & -490
\end{tabular}

in the temperature range from 293 to $313 \mathrm{~K}$, and up to 100 -fold cyclic scanning potential from -0.9 to $-1.2 \mathrm{~V}$. As shown in Fig. 2b, changes of the surface state during electrochemical influence lead to the formation of the oxide-hydroxide layers with complete morphology. As a result, the activity of the AMA in the electrocatalytical processes increases.
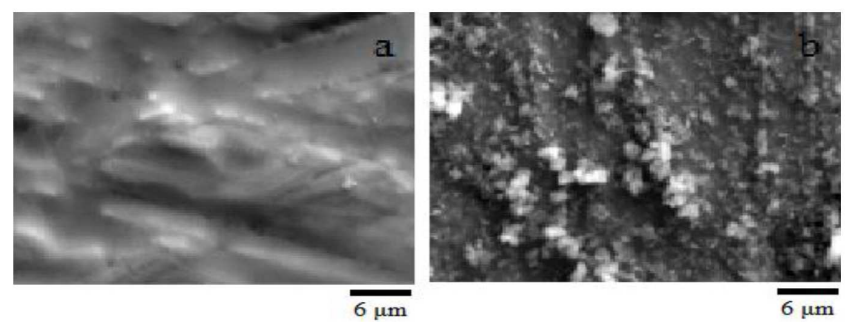

Fig. 2. Microphotos of the surface of the initial AMAelectrode $\mathrm{Fe}_{84} \mathrm{Nb}_{2} \mathrm{~B}_{14}$ before (a) and after electrochemical reaction (b) in $5.0 \mathrm{M} \mathrm{KOH}$ solution.

TABLE III

Dependence of the exchange current density $\left(\mathrm{mA} / \mathrm{cm}^{2}\right)$ of the initial (in) and pre-oxidized (ox) AMA in $5.0 \mathrm{M}$ $\mathrm{KOH}$ solution, $T=293 \pm 0.5 \mathrm{~K}$.

\begin{tabular}{c|c|c|c|c}
\hline \hline \multirow{2}{*}{ AMA } & \multicolumn{2}{|c|}{ Cycle No. 1 } & \multicolumn{2}{c}{ Cycle No. 100 } \\
\cline { 2 - 5 } & $i^{i n}\left(\mathrm{H}_{2}\right)$ & $i^{\text {ox }}\left(\mathrm{H}_{2}\right)$ & $i^{i n}\left(\mathrm{H}_{2}\right)$ & $i^{\text {ox }}\left(\mathrm{H}_{2}\right)$ \\
\hline $\mathrm{Fe}_{84} \mathrm{Nb}_{2} \mathrm{~B}_{14}$ & 10.18 & 7.08 & 10.4 & 7.53 \\
\hline $\mathrm{Fe}_{82} \mathrm{Nb}_{2} \mathrm{~B}_{14} \mathrm{~Tb}_{2}$ & 13.54 & 6.30 & 13.54 & 7.85 \\
\hline $\mathrm{Fe}_{82} \mathrm{Nb}_{2} \mathrm{~B}_{14} \mathrm{Dy}_{2}$ & 11.22 & 6.28 & 11.22 & 7.78
\end{tabular}

Amorphous alloys doped by $\mathrm{Tb}$ and Dy exhibit high corrosion resistance in aggressive alkaline environment. In Figs. 3a,c and 4a,c microphotos are shown of the surfaces of initial alloys with the addition of $\mathrm{Tb}$ and Dy after 100 -fold cyclic scanning potential in 5.0 M KOH aqueous solution at $303 \mathrm{~K}$ and $313 \mathrm{~K}$.

It is evident that the surface covered with thick protective layers does not change during the electrochemical reaction. The previously immersed samples of $\mathrm{Fe}_{82} \mathrm{Nb}_{2} \mathrm{~B}_{14} \mathrm{~Tb}_{2}$ for $24 \mathrm{~h}$ in $5.0 \mathrm{M} \mathrm{KOH}$ solution and after electrochemical reaction covered by developing oxides and hydro-oxides of globular form. On the other hand, the $\mathrm{Fe}_{82} \mathrm{Nb}_{2} \mathrm{~B}_{14} \mathrm{Dy}_{2}$ sample exhibited needle-like formations.

Increasing the temperature of the reaction medium actively accelerates the oxide-reduction processes not only of hydrogen evolution, but also of the destruction of the electrode surface.
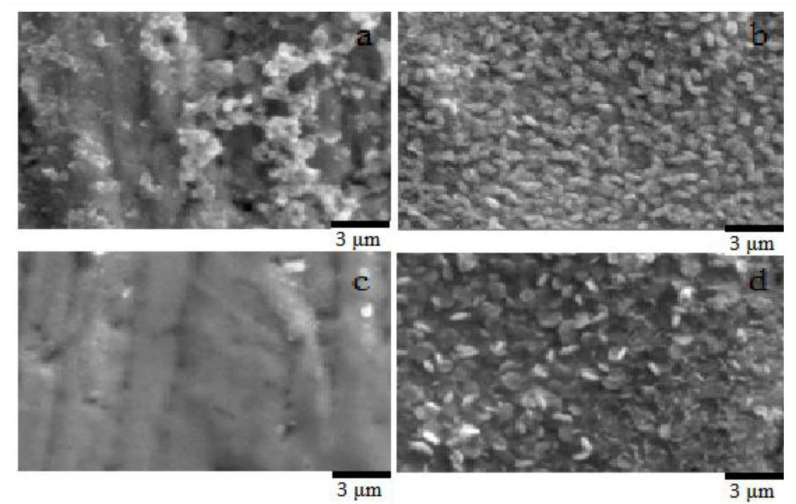

Fig. 3. Microphotos of the surface of the AMAelectrodes $\mathrm{Fe}_{82} \mathrm{Nb}_{2} \mathrm{~B}_{14} \mathrm{~Tb}_{2}$ after hydrogen evolution reaction on the initial $(\mathrm{a}, \mathrm{c})$ and pre-oxidized $(\mathrm{b}, \mathrm{d})$ surfaces in $5.0 \mathrm{M} \mathrm{KOH}$ solution at $303 \mathrm{~K}(\mathrm{a}, \mathrm{b})$ and $313 \mathrm{~K}(\mathrm{c}, \mathrm{d})$.
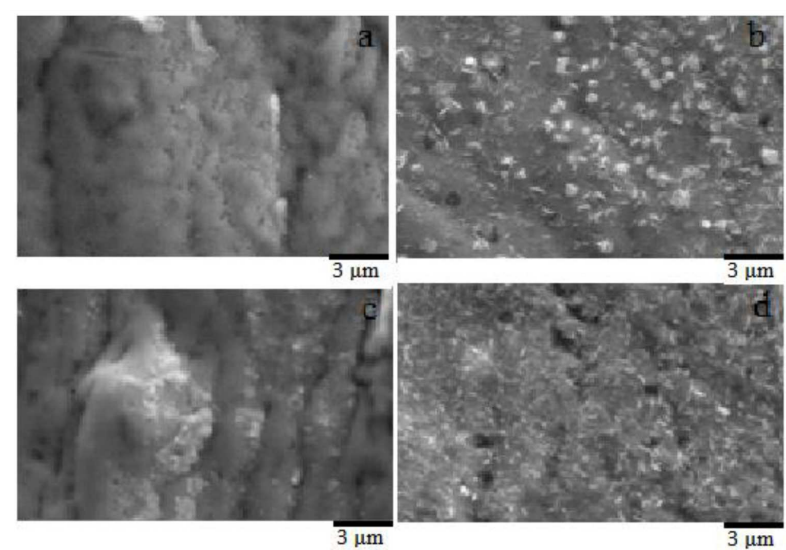

Fig. 4. Microphotos of the surface of the AMAelectrodes $\mathrm{Fe}_{82} \mathrm{Nb}_{2} \mathrm{~B}_{14} \mathrm{Dy}_{2}$ after hydrogen evolution reaction on the initial $(\mathrm{a}, \mathrm{c})$ and pre-oxidized $(\mathrm{b}, \mathrm{d})$ surfaces in $5.0 \mathrm{M} \mathrm{KOH}$ solution at $303 \mathrm{~K}(\mathrm{a}, \mathrm{b})$ and $313 \mathrm{~K}(\mathrm{c}, \mathrm{d})$.

Due to the fact that $\mathrm{Tb}$ may produce oxidation level $3+$ and $4+$, and Dy - mostly 3+, we can assume the mixed oxides on $\mathrm{Fe}_{82} \mathrm{Nb}_{2} \mathrm{~B}_{14} \mathrm{RE}_{2}$ quickly lead the surface to equilibrium state, and its catalytic activity remains.

Table IV shows the results of a study of the temperature dependence of the current density, defined from the Tafel slopes, on initial and oxidized surfaces of all the researched alloys at different temperatures of the electrolyte, and after 1 and 100 cycle scans of the potential. These data were used for characterization of change of the specific surface of the electrode due to the electro- 
catalytic reactions. The decrease of the values of $i^{o x}$ for the samples indicates an increase in the firmness of oxidized surface of alloys with increasing temperature of corrosive environment. The initial samples doped with $\mathrm{Tb}$ and Dy show higher activity compared with the basic $\mathrm{Fe}_{84} \mathrm{Nb}_{2} \mathrm{~B}_{14}$ sample in the 1st and 100th cycles. Characteristics of the $\mathrm{Fe}_{82} \mathrm{Nb}_{2} \mathrm{~B}_{14} \mathrm{Dy}_{2}$ AMA-electrode during multiple potential scanning are more stable compared with those for $\mathrm{Fe}_{82} \mathrm{Nb}_{2} \mathrm{~B}_{14} \mathrm{~Tb}_{2}$-electrode. For these alloys with increasing temperature the current density difference $\left(\Delta i\left(\mathrm{H}_{2}\right)=\left|i_{100}^{i n}-i_{1}^{i n}\right|\right)$ between the 1st and 100th cycles decreases because of the hardening of the protection surface layers after heating aggressive environment (Table IV). Both AMA electrodes exhibit high electrocatalytic activity in HER as the activation energies $\left(E_{a}\right)$, which are listed in Table $\mathrm{V}$, are low.

\section{TABLE IV}

Dependence of the exchange current density $i\left(\mathrm{H}_{2}\right)$ $\left[\mathrm{mA} / \mathrm{cm}^{2}\right]$ of the initial (in) and preoxidized (ox) AMA electrodes during scan potential cycle 1 and 100 at temperature of $5.0 \mathrm{M} \mathrm{KOH}$ solution.

\begin{tabular}{c|c|c|c|c|c|c}
\hline \hline \multirow{2}{*}{$T(\mathrm{~K})$} & Cycle 1 & \multicolumn{2}{c|}{ Cycle 100} & \multirow{2}{*}{$\Delta i^{i n}$} & \multirow{2}{*}{$\Delta i^{\text {ox }}$} \\
\cline { 2 - 5 } & $i^{\text {in }}$ & $i^{\text {ox }}$ & $i^{\text {in }}$ & $i^{\text {ox }}$ & & \\
\hline \multicolumn{7}{c}{$\mathrm{Nb}_{2} \mathrm{~B}_{14}$} \\
\hline 293 & 10.18 & 7.08 & 9.68 & 7.53 & 0.50 & 0.45 \\
\hline 298 & 9.76 & 6.97 & 9.66 & 5.53 & 0.10 & 1.44 \\
\hline 303 & 9.79 & 6.56 & 10.08 & 6.38 & 0.32 & 0.18 \\
\hline 313 & 9.66 & 6.71 & 8.67 & 7.11 & 0.90 & 0.40 \\
\hline \multicolumn{7}{c}{$\mathrm{Fe}_{82} \mathrm{Nb}_{2} \mathrm{~B}_{14} \mathrm{~Tb}_{2}$} \\
\hline 293 & 13.54 & 6.30 & 12.24 & 7.85 & 1.30 & 1.55 \\
\hline 298 & 11.94 & 5.02 & 12.13 & 4.40 & 0.19 & 0.62 \\
\hline 303 & 12.26 & 3.94 & 13.82 & 4.28 & 1.56 & 0.34 \\
\hline 313 & 12.40 & 4.21 & 12.18 & 4.27 & 0.22 & 0.06 \\
\hline \multicolumn{7}{|c}{$\mathrm{Fe}_{82} \mathrm{Nb}_{2} \mathrm{~B}_{14} \mathrm{Dy}_{2}$} \\
\hline 293 & 11.22 & 6.28 & 11.19 & 7.78 & 0.03 & 1.50 \\
\hline 298 & 11.11 & 4.95 & 11.14 & 4.42 & 0.03 & 0.53 \\
\hline 303 & 10.73 & 4.15 & 11.38 & 4.23 & 0.65 & 0.08 \\
\hline 313 & 10.93 & 4.13 & 11.59 & 4.24 & 0.66 & 0.11
\end{tabular}

TABLE V

Activation energies $(\mathrm{kJ} / \mathrm{mol})$ of the HER on different AMA electrodes within the potentials from -1.3 to $0.95 \mathrm{~V}$ (potential scan cycles 1 and 100).

\begin{tabular}{c|c|c|c|c}
\hline \hline \multirow{2}{*}{$\mathrm{AMA}$} & \multicolumn{2}{|c|}{$E_{a}(\mathrm{~T}=293-303 \mathrm{~K})$} & \multicolumn{2}{c}{$E_{a}(\mathrm{~T}=303-313 \mathrm{~K})$} \\
\cline { 2 - 5 } & Cycle 1 & Cycle 100 & Cycle 1 & Cycle 100 \\
\hline $\mathrm{Fe}_{84} \mathrm{Nb}_{2} \mathrm{~B}_{14}$ & 3.83 & 3.83 & 1.72 & 13.9 \\
\hline $\mathrm{Fe}_{82} \mathrm{Nb}_{2} \mathrm{~B}_{14} \mathrm{~Tb}_{2}$ & 5.74 & 9.57 & 3.83 & 7.66 \\
\hline $\mathrm{Fe}_{82} \mathrm{Nb}_{2} \mathrm{~B}_{14} \mathrm{Dy}_{2}$ & 2.01 & 4.50 & 1.91 & 3.83
\end{tabular}

Activation energy of hydrogen evolution on the $\mathrm{Fe}_{82} \mathrm{Nb}_{2} \mathrm{~B}_{14} \mathrm{~Tb}_{2}$-electrode is slightly higher compared to the $\mathrm{Fe}_{82} \mathrm{Nb}_{2} \mathrm{~B}_{14} \mathrm{Dy}_{2}$-electrode. However, the $\mathrm{Tb}$ alloy exhibits higher corrosion resistance of the surface at higher temperatures in 5.0 M KOH solution and higher stability of its parameters in multiscanned processes. These characteristics make this alloy the most promising one for practical application as an electrode in HER. The lower activation energy in the case of electrocatalysis on $\mathrm{Fe}_{84} \mathrm{Nb}_{2} \mathrm{~B}_{14}, \mathrm{Fe}_{82} \mathrm{Nb}_{2} \mathrm{~B}_{14} \mathrm{Dy}_{2}$-electrodes compared to $\mathrm{Fe}_{82} \mathrm{Nb}_{2} \mathrm{~B}_{14} \mathrm{~Tb}_{2}$-electrode could be explained by similar parameters of corrosion processes and HER, which took place on the cathode surface.

The limiting stage in the electrocatalytic HER is the process of transport of $\mathrm{OH}^{-}$groups from an aqueous solution to the electrode surface. The RE alloying elements in AMA-electrodes are responsible for their higher corrosive strength and stability of electrocatalytic activity during the cyclic scanning of the potential. Rare earths also promote formation of insoluble oxide-hydroxide surface layers which slow down the charge transfer to the electrode surface, consequently, a slight increase of the activation energy is observed. However, this does not relate to the kinetic stage of the process, which happens instantly, but slows down molization of the adsorbed hydrogen $\left(\mathrm{H}_{a d s}\right)$ in dense surface layers.

\section{Conclusions}

The ribbons of three amorphous Fe-based metallic alloys were prepared by melt spinning method. A basic ternary sample $\mathrm{Fe}_{84} \mathrm{Nb}_{2} \mathrm{~B}_{14}$ was alloyed with 2 at.\% RE $=\mathrm{Tb}$ or Dy: $\mathrm{Fe}_{82} \mathrm{Nb}_{2} \mathrm{~B}_{14} \mathrm{~Tb}_{2}, \mathrm{Fe}_{82} \mathrm{Nb}_{2} \mathrm{~B}_{14} \mathrm{Dy}_{2}$.

During repeated scanning of the potential in the range from -1.0 to $+0.4 \mathrm{~V}$ a process at $\approx-0.3 \mathrm{~V}$ becomes a predominant one for all investigated AMAs. A surface of the basic AMA electrode $\mathrm{Fe}_{84} \mathrm{Nb}_{2} \mathrm{~B}_{14}$ is the most amenable to dissolution. Additions of rare earths reduce the solubility of the surface of AMAs. It is especially noticeable in the case of $\mathrm{Tb}$ and Dy alloys.

The limiting stage in electrocatalytic HER is the process of transport of $\mathrm{OH}^{-}$groups from an aqueous solution to the electrode surface. The alloying elements in AMA-electrodes are responsible for their high corrosion strength and stable electrocatalytic activity during the cyclic scanning of the potential. Rare earths also promote the formation of insoluble oxide-hydroxide surface layers which slow down the charge transfer to the electrode surface, consequently, a slight increase of the activation energy of the HER during multiscanned process is observed. However, this does not relate to the kinetic stage of the process, which happens instantly.

\section{References}

[1] F. Safizadeh, E. Ghali, G. Houlachi, Int. J. Hydrogen En. 40, 256 (2015).

[2] K.C. Neyerlin, W. Gu, J. Jorne, H.A. Gasteiger, J. Electrochem. Soc. 154, B631 (2007).

[3] Y.D. Wang, Y.I. Cao, Electrochem. Commun. 6, 780 (2004).

[4] Kang Cheol Kim, Ka Ram Lim, Sung Hyun Park, Min Young Na, Won Tae Kim, Do Hyang Kim, Corros. Sci. 88, 209 (2014).

[5] C.A.C. Sequeira, D.M.F. Santos, P.S.D. Brito, Energy 36, 847 (2011). 
[6] V.I. Lysov, T.L. Tsaregradskaya, O.V. Turkov, Sci. Notes Taurida National VI Vermadsky Univ. Phys. Math. Sci. 25, 184 (2012)

[7] K.R. Lim, J.M. Park, S.J. Kim, E.S. Lee, W.T. Kim, A. Gebert, J. Eckert, D.H. Kim, Corros. Sci. 77, 1 (2013).

[8] M.U. Kleinke, M. Knobel, L.O. Bonugli, O. Teschke, Int. J. Hydrogen En. 22, 759 (1997).

[9] S.L. Wang, D.H. Kim, S. Yi, Korean J. Chem. Eng. 28, 1672 (2011).

[10] H. Metikos-Hukovic, A. Jukic, Electrochim. Acta 45, 4159 (2000)

[11] B.E. Conway, B.V. Tilak, Electrochim. Acta 47, 3571 (2002).
[12] A. Chrobak, V. Nosenko, G. Haneczok, L. Boichyshyn, B. Kotur, A. Bajorek, O. Zivotsky, A. Hendrych, Mater. Chem. Phys. 48, 555 (2011).

[13] L. Bednarska, J. Kubisztal, A. Budniok, M. Kovbuz, O. Hertsyk, T. Mika, B. Kotur, J. Phys. Conf. Ser. 289, 012019 (2011).

[14] R.K. Shervedani, A.R. Madran, Int. J. Hydrogen En. 33, 2843 (2008).

[15] M. Pourbaix, Atlas of Electrochemical Equilibria in Aqueous Solutions, JW Arrowsmith, Bristol 1966. 